\title{
When metabolic prowess is too much of a good thing: how carbon catabolite repression and metabolic versatility impede production of esterified $a, \omega$-diols in Pseudomonas putida KT2440
}

Chunzhe Lu' ${ }^{1}$, Christos Batianis ${ }^{2}$, Edward Ofori Akwafo ${ }^{1}$, Rene H. Wijffels ${ }^{1,4}$, Vitor A. P. Martins dos Santos ${ }^{1,2,3}$ and Ruud A. Weusthuis ${ }^{1 *}$ (1)

\begin{abstract}
Background: Medium-chain-length a, $\omega$-diols (mcl-diols) are important building blocks in polymer production. Recently, microbial mcl-diol production from alkanes was achieved in E. coli (albeit at low rates) using the alkane monooxygenase system AlkBGTL and esterification module Atf1. Owing to its remarkable versatility and conversion capabilities and hence potential for enabling an economically viable process, we assessed whether the industrially robust P. putida can be a suitable production organism of mcl-diols.
\end{abstract}

Results: AlkBGTL and Atf1 were successfully expressed as was shown by oxidation of alkanes to alkanols, and esterification to alkyl acetates. However, the conversion rate was lower than that by E. coli, and not fully to diols. The conversion was improved by using citrate instead of glucose as energy source, indicating that carbon catabolite repression plays a role. By overexpressing the activator of AlkBGTL-Atf1, AlkS and deleting $\operatorname{Crc}$ or CyoB, key genes in carbon catabolite repression of P. putida increased diacetoxyhexane production by $76 \%$ and $65 \%$, respectively. Removing $\mathrm{Crc} / \mathrm{Hfq}$ attachment sites of mRNAs resulted in the highest diacetoxyhexane production. When the intermediate hexyl acetate was used as substrate, hexanol was detected. This indicated that P. putida expressed esterases, hampering accumulation of the corresponding esters and diesters. Sixteen putative esterase genes present in $P$. putida were screened and tested. Among them, Est12/K was proven to be the dominant one. Deletion of Est $12 / \mathrm{K}$ halted hydrolysis of hexyl acetate and diacetoxyhexane. As a result of relieving catabolite repression and preventing the hydrolysis of ester, the optimal strain produced $3.7 \mathrm{mM}$ hexyl acetate from hexane and $6.9 \mathrm{mM}$ 6-hydroxy hexyl acetate and diacetoxyhexane from hexyl acetate, increased by 12.7- and 4.2-fold, respectively, as compared to the starting strain.

Conclusions: This study shows that the metabolic versatility of P. putida, and the associated carbon catabolite repression, can hinder production of diols and related esters. Growth on mcl-alcohol and diol esters could be prevented by deleting the dominant esterase. Carbon catabolite repression could be relieved by removing the $\mathrm{Crc} / \mathrm{Hfq}$ attachment

*Correspondence: ruud.weusthuis@wur.nl

${ }^{1}$ Bioprocess Engineering, Wageningen University and Research, Wageningen, The Netherlands

Full list of author information is available at the end of the article permits use, sharing, adaptation, distribution and reproduction in any medium or format, as long as you give appropriate credit to the original author(s) and the source, provide a link to the Creative Commons licence, and indicate if changes were made. The images or other third party material in this article are included in the article's Creative Commons licence, unless indicated otherwise in a credit line to the material. If material is not included in the article's Creative Commons licence and your intended use is not permitted by statutory regulation or exceeds the permitted use, you will need to obtain permission directly from the copyright holder. To view a copy of this licence, visit http://creativecommons.org/licenses/by/4.0/. The Creative Commons Public Domain Dedication waiver (http://creativeco mmons.org/publicdomain/zero/1.0/) applies to the data made available in this article, unless otherwise stated in a credit line to the data. 
sites. This strategy can be used for efficient expression of other genes regulated by $\mathrm{Crc} / \mathrm{Hfq}$ in Pseudomonas and related species to steer bioconversion processes.

Keywords: Metabolic versatility, Substrate preference, Monooxygenase, Medium-chain-length a, $\omega$-diols, $\omega$-Oxyfunctionalization, Pseudomonas putida, Esterase

\section{Introduction}

\section{Pseudomonas putida: its versatile metabolism and carbon} catabolite repression system

Pseudomonas putida KT2440 is a well-known Gramnegative bacterium, increasingly attracting industrial attention. Its tolerance to chemical solvents [1], its ability to accumulate large amounts of mcl-PHA [2] and its increasingly available genetic tools [3] make $P$. putida KT2440 a promising chassis for the production of bulk chemicals [4-7]. P. putida KT2440 has a versatile metabolism, which is illustrated by its ability to grow on dozens of different carbon sources, including amino acids, alcohols and a wide range of lignin derivatives [8]. In its natural environment, soil, multiple carbon sources are available. To maximize its growth rate, $P$. putida KT2440 needs to select for a preferred substrate. This selection is precisely regulated by carbon catabolite repression (CCR) of essential genes for uptake and catabolism of non-preferred carbon sources [5].

The molecular mechanisms for carbon catabolite repression are primarily controlled by the $\mathrm{Crc}$ protein in Pseudomonas. Crc regulates the expression of over 130 genes in P. putida $[9,10]$ at the translation level, including those for assimilation of hydrocarbons, such as n-alkanes, benzoate and toluene. Crc forms a complex with the RNA-binding protein $\mathrm{Hfq}$ on its distal part in presence of an attachment site (A-rich motifs, AANAANAA) which is located near the translation initiation region of target mRNAs to inhibit translation (Fig. 1a). Except for $\mathrm{Crc}$, the cytochrome o ubiquinol oxidase (Cyo), a terminal oxidase of the electron transport chain, also conduces to catabolite repression. Cyo is considered to play an active role in cell growth under sufficient oxygen supply. Although the mechanism behind Cyo is still unknown, deleting $\mathrm{CyoB}$-coding the key gene of Cyo-relieves catabolite repression [11]. Knocking out $C r c$ and $C y o B$ at the same time showed a superimposed effect on relieving repression in rich medium [11].

These types of CCR systems are necessary for the robustness of microbes in their natural environments when facing multiple substrates, but may impede their performance in industrial biotransformations, in which desired products may act as preferred substrates over the applied substrate[5, 6].

\section{Microbial synthesis of medium-chain-length $a, \omega$-diols}

Medium-chain-length $\alpha, \omega$-diols (mcl-diols) are versatile chemicals used as fuels, detergents and precursors of polyesters and polyurethanes, which are the two primary sources for the production of biobased plastics [12-15]. 1,6 -Hexanediol is one of the common $\alpha, \omega$-diols, traditionally produced by hydrogenation of adipic acid [16].

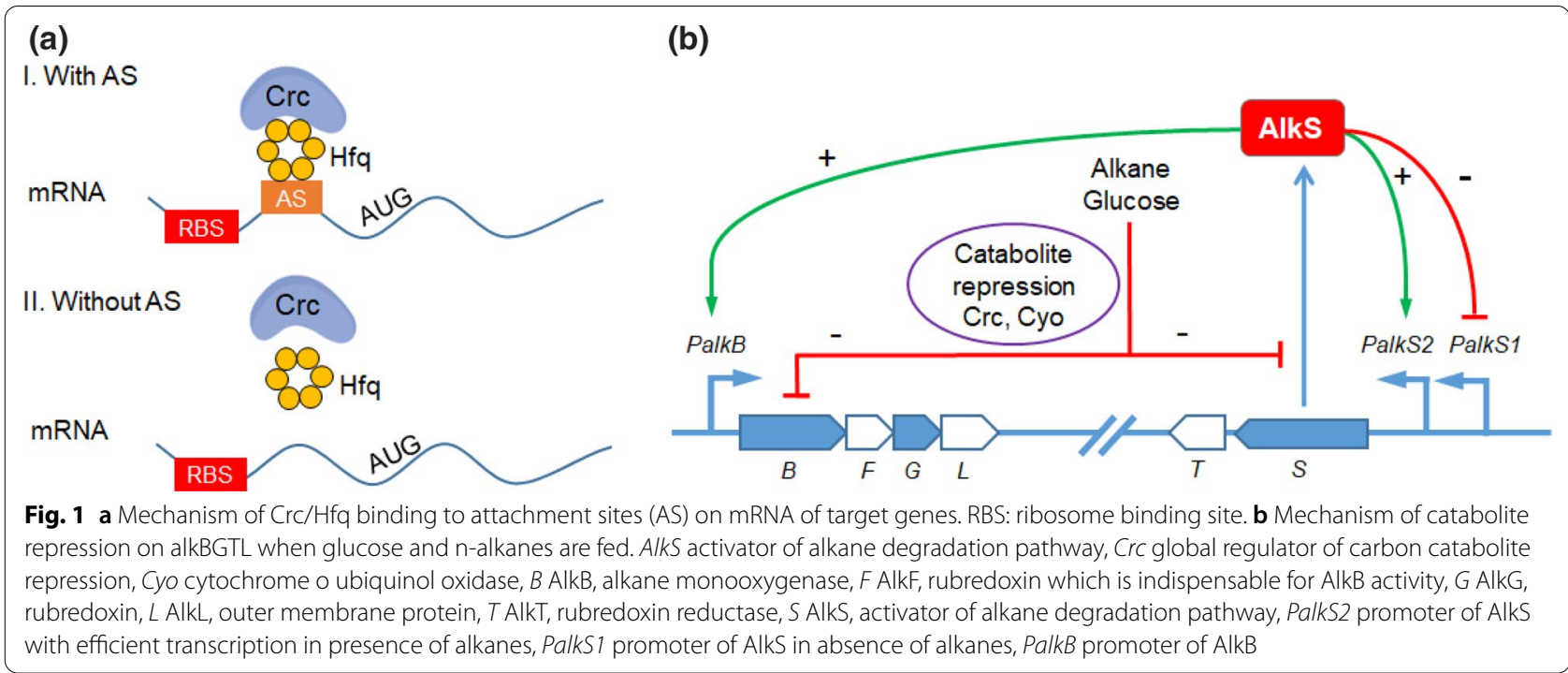


This process requires a high energy input and expensive catalysts, and it usually results in significant byproduct formation. Due to these unsustainable traits, microbial synthesis is attracting more and more attention as a promising alternative solution $[17,18]$.

Van Nuland and coworkers investigated the conversion of medium-chain alkanes and alkanols into mcl-diols by $E$. coli, by expressing the monooxygenase system AlkBGT from Pseudomonas putida GPO1 [19]. In E. coli these enzymes act in an orthogonal fashion, as E. coli does not employ CCR by the Crc protein. Van Nuland et al. encountered two challenges: AlkBGT overoxidized hydroxyl groups and was unable to oxidize the terminal methyl group of alkanols. They solved the first challenge by protecting the hydroxyl groups by esterifying them with acetyl-CoA using the alcohol acetyltransferase Atf1 from Saccharomyces cerevisiae. Glucose was used to provide energy for maintenance and acetyl-CoA for esterification. The esterification of the first hydroxyl group also solved the second challenge as it enabled the $\omega$-oxidation of medium chain alkanol esters. The final products were diacetoxyalkanes: $\alpha, \omega$-diols esterified at both ends with acetate.

In P. putida GPO1, the alkBGT system is part of the alkane degradation pathway, encoded on the OCT plasmid [20]. AlkB, an integral membrane protein, is an alkane monooxygenase, inserting a single oxygen atom from molecular oxygen into a terminal carbon-hydrogen bond of $n$-alkanes. The soluble rubredoxin AlkG, which is reduced by the rubredoxin reductase AlkT, is responsible for delivering electrons to AlkB. AlkL is a transporter located in the periplasmic membrane, facilitating uptake of hydrophobic compounds [21,22]. The alkane degradation genes are split into two clusters, AlkST and AlkBFGHJKL (Fig. 1b). The whole pathway is activated by AlkS controlling the AlkST cluster by the promoter PalkS2 and the AlkBFGHJKL cluster by the promoter PalkB. In $P$. putida GPO1 the Crc protein inhibits translation of AlkS [20], AlkB and AlkG mRNAs to repress AlkBGT activity when cells grow on a minimal medium with preferred substrates such as succinate and lactate23, 24. P. putida KT2440 is relatively close to P. putida GPO1, and both share the carbon catabolite repression system mediated by $\mathrm{Crc}$ and Cyo $[25,26]$.

A next challenge in the sustainable microbial production of mcl-diols is to use sugars instead of alkanes as substrate. Owing to its remarkable metabolic versatility, oxidative capacity and industrial robustness, $P$. putida may prove to be a more suitable chassis than $E$. coli, also because of its innate ability to convert sugars into mclPHA using the fatty acid synthesis pathway. The intermediates of this pathway can serve as precursors for mcl-diol production. Also the tolerance of some P. putida species against chemical solvents such as mcl-diols and their acetate esters may attribute to this suitability [1, 27-29]. On the other hand, expression of AlkBGTL in the presence of glucose is subjected to carbon catabolite repression in $P$. putida and may result in low conversion rates. In addition, another potential issue is that the versatile metabolism of $P$. putida KT2440 possibly enables it to break down the diols and their acetate esters through enzymes like esterases [30].

In this study, $P$. putida KT2440 was engineered as a biocatalyst to produce esterified diols from alkanes by $\omega$-oxidation of alkyl acetate in the presence of glucose (Fig. 2). The monooxygenase system genes AlkBGTL and Atf1 were introduced in P. putida KT2440. To ensure efficient function of AlkBGTL, the catabolite repression control gene $(\mathrm{Crc})$ and the key gene of cytochrome o ubiquinol oxidase $(C y o B)$ were deleted. AlkS as the main activator of the whole oxidation and esterification pathway was overexpressed using the XylS/Pm promoter to counter the potential repression imposed by Crc. Moreover, when the XylS/Pm expression system was used to eliminate carbon catabolite repression, the A-rich motifs of $A l k B, A l k G$, and Atf1, representing Crc/ Hfq attachment sites, were deleted. Alcohol acetyltransferase (Atf1) was expressed to prevent overoxidation and enable terminal oxidation of alcohols. We identified and tested esterases responsible for hydrolysis of alkyl acetate and diol diacetate esters. The dominant esterase was deleted to prevent alkyl acetate from being hydrolysed and to ensure accumulation of esterified diols. This study explores the potential and eliminates hurdles of $P$. putida KT2440 to make it an efficient chassis to further synthesize diols and esters. The strategy can be potentially used for efficient expression of other genes regulated by $\mathrm{Crc} /$ Hfq in Pseudomonas and related species.

\section{Results and discussion}

Introducing AlkBGTL-Atf1 into P. putida KT2440

AlkBGTL alone and in combination with Atf1 was introduced into $P$. putida KT2440, resulting in strains P-BGTL and P-BGTLA, respectively. To test the proper functioning of the enzymes, $\mathrm{n}$-hexane and hexyl acetate were separately used as substrates in 1-mL resting-cell suspensions with $\mathrm{OD}_{600}$ of 3 . When $1 \% \mathrm{v} / \mathrm{v}$ n-hexane $(76 \mathrm{mM})$ was fed in the resting-cell suspensions, P-BGTL produced $0.3 \mathrm{mM}$ 1-hexanol while P-BGTLA produced $2.0 \mathrm{mM}$ 1-hexanol and $0.3 \mathrm{mM}$ hexyl acetate (Fig. 3a) after $20 \mathrm{~h}$. Strain P-L, harboring the substrate transporter alkL, was used as a negative control strain, and did not produce any of these compounds. These results show that both AlkBGTL and Atf1 were successfully expressed in $P$. putida. It was observed that the presence of Atf1 facilitated the production of oxidized products (hexanol and 

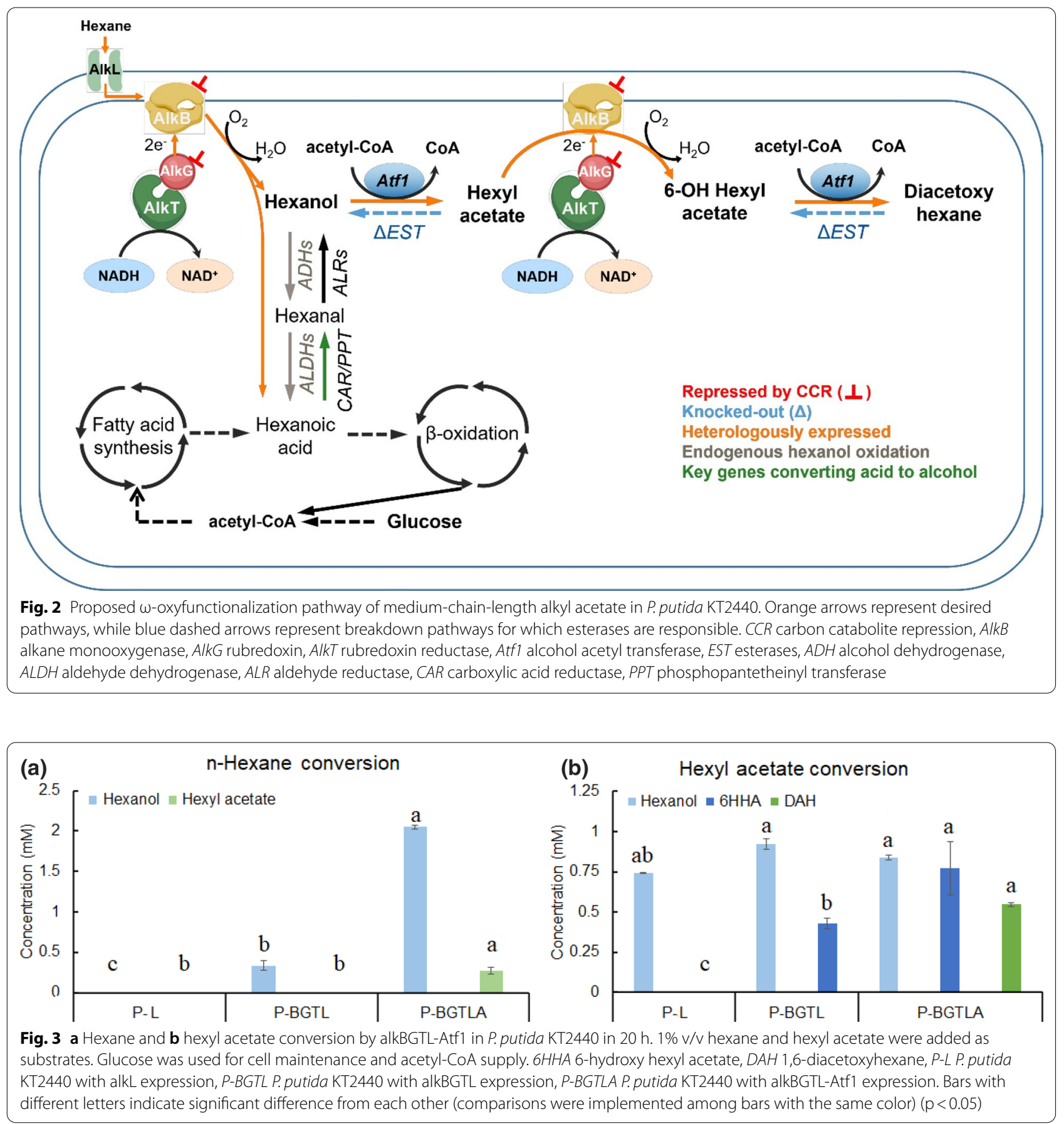

hexyl acetate). P-BGTLA produced far more 1-hexanol than hexyl acetate indicating that either Atf1 is the ratelimiting step or that hexyl acetate produced by Atf1 was hydrolyzed back to 1-hexanol by esterases present in $P$. putida KT2440. Similar experiments have been performed in E. coli by van Nuland et al. [19]. When $1 \% \mathrm{v} / \mathrm{v}$ n-hexane was fed to E. coli harboring AlkBGTL, over $95 \%$ of the total products were overoxidized (hexanoic acid) and minor amounts of 1-hexanol were detected. E. coli harboring AlkBGTL-Atf1 produced $9.20 \mathrm{mM}$ 1,6-diacetoxyhexane as the major product and $2.23 \mathrm{mM}$ 6-hydroxy hexyl acetate under same conditions described above. However, hexanoic acid, 6-hydroxy hexyl acetate and 1,6-diacetoxyhexane were not found in our conversions. This may be attributed to a low activity of AlkBGTL in P. putida KT2440 resulting from carbon 
catabolite repression. Similarly, when n-hexane was fed, 1,6-diacetoxyhexane and 6-hydroxy hexyl acetate were not detected in P-BGTLA. We questioned that AlkBGTL-Atf1 could not convert hexyl acetate into 6-hydroxy hexyl acetate and 1,6-diacetoxyhexane in P. putida.

To test if hexyl acetate can be converted by AlkBGTLAtf1, $1 \% \mathrm{v} / \mathrm{v}$ of hexyl acetate $(60 \mathrm{mM})$ was fed to P-L, P-BGTL and P-BGTLA. In a 20-h conversion, $0.77 \mathrm{mM}$ 6-hydroxy hexyl acetate and $0.55 \mathrm{mM} \mathrm{1,6-diacetoxyhex-}$ ane were detected in P-BGTLA (Fig. 3b). This proves that AlkBGTL-Atf1 is able to $\omega$-oxidize hexyl acetate in P. putida KT2440, however, more alcohol products were produced compared to the diester production. 1-Hexanol was found in all strains when hexyl acetate was fed, indicating that esterases were functioning, resulting in the hydrolysis of hexyl acetate to hexanol and acetate.

\section{Catabolite repression on AlkBGTL-Atf1}

In all experiments, glucose was added to provide energy for maintenance and acetyl-CoA for ester bond formation by Atf1 under resting-cell conditions. n-Hexane or hexyl acetate was fed as substrate to produce hexyl acetate and diacetoxyhexane. However, $P$. putida KT2440 prefers glucose over $n$-hexane and hexyl acetate, triggering activation of carbon catabolite repression to repress expression and translation of AlkBGTL [10]. To test this hypothesis, we tried citrate instead of glucose as it was reported that citrate does not activate carbon catabolite repression of the alkane degradation pathway [10]. Compared to glucose, the production of 6-hydroxy hexyl acetate from hexyl-acetate was increased by $66.9 \%$ on citrate reaching $1.5 \mathrm{mM}$ (Fig. 4a). This is in agreement with our hypothesis that glucose represses AlkBGTL function in $P$. putida KT2440.

To tackle glucose repression on a molecular level, we used three approaches: (i) knocking out the carbon catabolite repression genes $\mathrm{Crc}$ and/or $\mathrm{CyoB}$; (ii) increasing the expression of the AlkS activator; (iii) removing the $\mathrm{Crc} / \mathrm{Hfq}$ attachment sites from the AlkBGTL-Atf1 genes.

We deleted $C r c$ and $C y o B$, either separately or together, and the mutants were transformed with $A l k L$, AlkBGTL and AlkBGLT-Atf1 to investigate the effects of the regulators on the activity of AlkBGTL, and AlkBGTL-Atf1. It was shown that all mutants, especially the

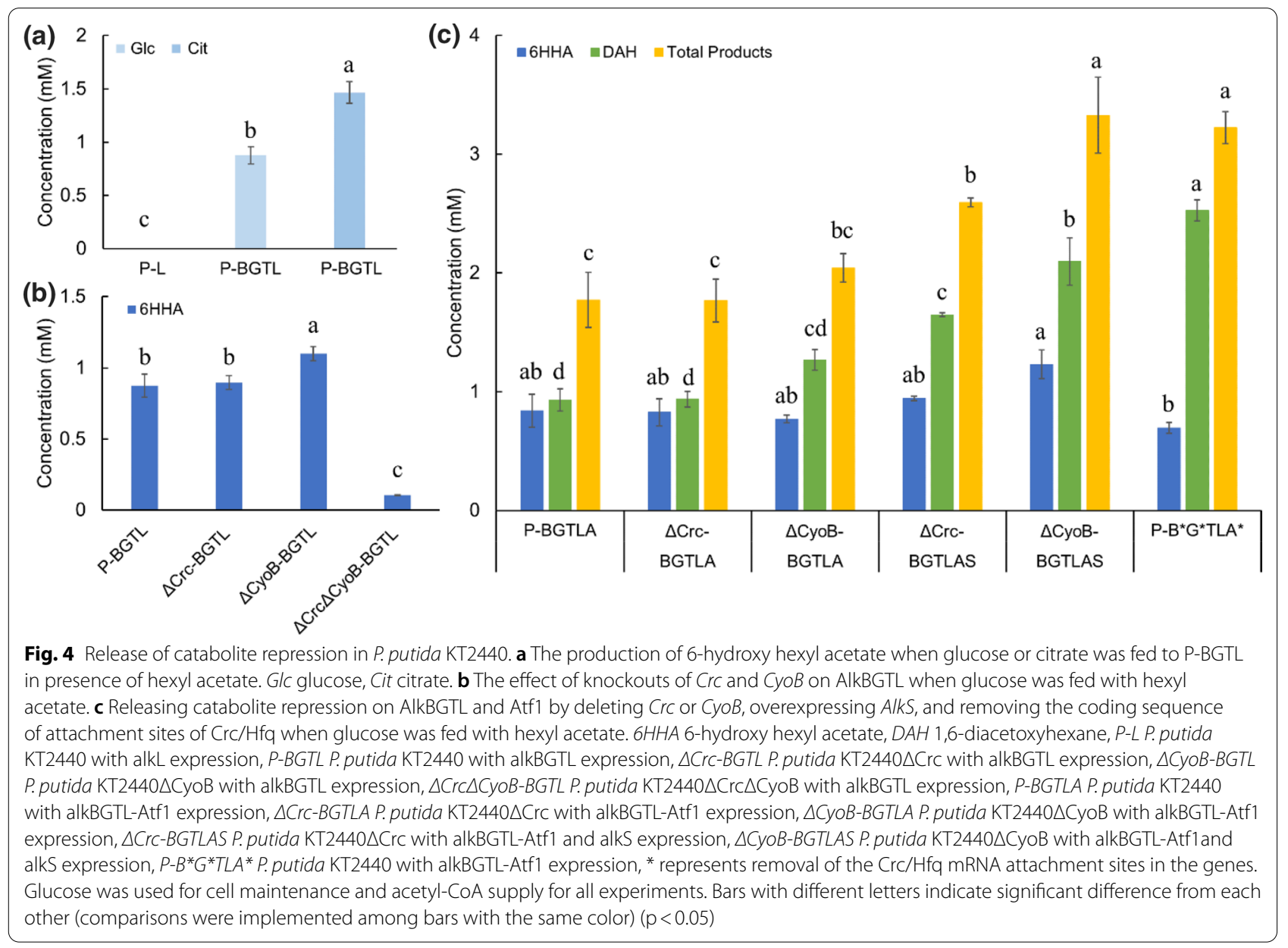


double-knockout strain $\Delta C r c \Delta C y o B$, grew significantly slower than the wild-type strain (results not shown). The results with hexyl acetate as substrate are shown in Fig. 4b when only AlkBGTL was expressed. It shows that the $\mathrm{Crc}$ knockout had no effect on 6-hydroxy hexyl acetate production and that the $C y o B$ knockout increased 6-hydroxy hexyl acetate by $25.6 \%$. When both $\mathrm{Crc}$ and $\mathrm{CyoB}$ were deleted, 6-hydroxy hexyl acetate production reduced with $88.0 \%$. This conflicts with previous research performed by Dinamarca and his colleagues [11] who showed that $\mathrm{Crc}$ and Cyo have an additive influence on the alkane degradation pathway. However, they used the lacZ gene as an orthogonal reporter to replace alkane degradation genes to test how knockouts affect gene expression under the control of the promoter PalkB. In our case, AlkBGTL was directly used to produce 6-hydroxy hexyl acetate, and was connected to the rest of metabolism, e.g. due to $\mathrm{NADH}$ requirement. Because deletion of $\mathrm{CrC}$ and $\mathrm{CyoB}$ will affect the expression of many genes [31], the whole metabolism will be significantly changed, which may have led to poor availability of NADH. This may be the reason why strain $\Delta \mathrm{Crc} \Delta \mathrm{CyoB}-\mathrm{BGTL}$ only produced trace amounts of 6-hydroxy hexyl acetate.

To test the performance of AlkBGTL-Atf1 in the knockouts strains, the plasmid pBGTL-Atf1 was separately introduced, generating strains P-BGTLA, $\triangle \mathrm{Crc}$ BGTLA, and $\triangle$ CyoB-BGTLA. Compared to P-BGTLA, $\triangle$ Crc-BGTLA produced the same amount of 6-hydroxy hexyl acetate and diacetoxyhexane (Fig. 4c), indicating that the $\mathrm{Crc}$ knockout cannot increase AlkBGTL-Atf1 activity. The diacetoxyhexane production by strain $\triangle$ CyoB-BGTLA increased by $36.5 \%$ in comparison with the P-BGTLA strain, indicating that esterification was improved. The knockout of $C y o B$ might release the repression on Atf1 or limit electron transport chain to provide more acetyl-CoA to Atf1. In AlkBGTL-Atf1 case, not only $A l k S, A l k B$, and $A l k G$, but also Atf1 were repressed because Atf1 was controlled by PalkB too. However, because Crc represses the alkane degradation pathway mainly through reducing the expression level of $A l k S$, which is the activator of the whole pathway, AlkS was reportedly overexpressed to counter repression of $\mathrm{Crc}$ on the pathway [24]. In this work, pSEVAb628-AlkS was, respectively, transformed into strains $\triangle$ Crc-BGTLA and $\triangle$ CyoB-BGTLA, giving rise to strains $\triangle$ Crc-BGTLAS and $\triangle$ CyoB-BGTLAS to overexpress AlkS. Strain $\triangle$ Crc-BGTLAS produced $14 \%$ more 6-hydroxy hexyl acetate and 76\% more diacetoxyhexane, while strain $\triangle$ CyoB-BGTLAS produced $60 \%$ more 6-hydroxy hexyl acetate and 65\% more diacetoxyhexane (Fig. 4c). But, because $\mathrm{Crc}$ and $\mathrm{Cyo}$ are global regulators, knocking them out affects the whole metabolism of $P$. putida, as indicated by the reduced growth rates.

To establish less pleiotropy, we decided to remove the sequences encoding the mRNA attachment sites of the $\mathrm{Crc} / \mathrm{Hfq}$ complex from the overexpressed genes. The attachment sites in front of $A l k B, A l k G$ and Atf1 were removed, generating a plasmid pSEVAb658-alkB"G"TLAtf1"(Fig. 5), which was subsequently transformed into P. putida KT2440 resulting in strain P-B"G"TLA". Compared with P-BGTLA, the total production of P-B"G"TLA" was increased by $82 \%$. Among all five tested strains ( $\triangle$ Crc-BGTLA, $\triangle$ CyoB-BGTLA, $\triangle$ Crc-BGTLAS, $\triangle$ CyoB-BGTLAS, and P-B"G"TLA"), $\triangle$ CyoB-BGTLAS and P-B"G"TLA" were the two best-performing strains, producing 3.3 and $3.2 \mathrm{mM}$ total products (6-hydroxy hexyl acetate and diacetoxyhexane), respectively (Fig. 4c). The difference between $\triangle \mathrm{CyoB}-\mathrm{BGTLAS}$ and P-B"G"TLA" was the ratio of 6-hydroxy hexyl acetate and diacetoxyhexane. P-B"G"TLA" showed the highest diacetoxyhexane concentration $(2.52 \mathrm{mM})$ while $\triangle \mathrm{CyoB}$ BGTLAS generated the highest 6-hydroxy hexyl acetate concentration (1.2 $\mathrm{mM})$. AlkS was overexpressed in $\triangle$ CyoB-BGTLAS to ensure high expression of AlkBGTLAtf1 to counter carbon catabolite repression, leading to the highest total products. But 6-hydroxy hexyl acetate is not fully converted to diacetoxyhexane, indicating esterification of 6HHA is still limited. P-B"G"TLA" significantly released the inhibition of Atf1, facilitating higher production of diacetoxyhexane. The plasmid pSEVA658B"G"TL-Atf1" was used for further tests, given its high production and lower pleiotropy.

\section{Growth test of $P$. putida KT2440 on hexyl acetate and DAH}

P. putida KT2440, known for its versatile metabolism, can grow on dozens of different carbon sources [5-8]. To date, it is unknown whether $P$. putida KT2440 can utilize aliphatic acetate esters and diesters for growth. In our study, hexyl acetate was hydrolyzed to hexanol (Fig. 3b), which can be easily further utilized via $\beta$-oxidation. Thus, we assumed $P$. putida KT2440 is able to use hexyl acetate and diacetoxyhexane as the only carbon source for growth, in which esterases perform the first step, the hydrolysis of esters. If so, this is a potential threat for $P$. putida KT2440 to be engineered for hexyl acetate and diacetoxyhexane production.

Wild-type P. putida KT2440 was used for growth tests on M9 medium with $10 \mathrm{mM}$ hexyl acetate or diacetoxyhexane as the only carbon source. The hexyl acetate case (Fig. 6a) showed a $48 \mathrm{~h}$ lag phase, after which the biomass concentration increased quickly and the hexyl acetate concentration decreased. In the end, $95 \%$ of the initially added hexyl acetate was consumed and the optical density reached its maximum at 1.15 with an $\mathrm{OD}_{600}$ 
(a) pBGTL-Atf1

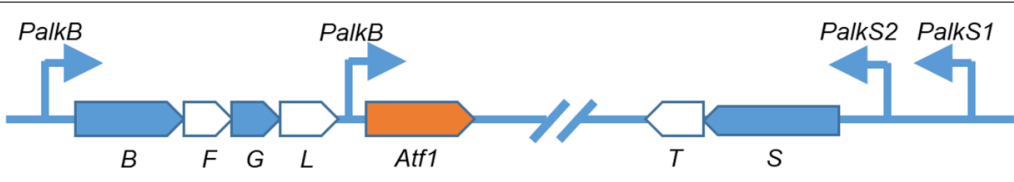

\begin{tabular}{ll}
\hline Gene & RNA sequence (Crc/Hfq binding site in yellow color) \\
\hline alkS & CAUAAUGAAAUAAUAAUAAUAAUGAUUUCCCGGCGCU \\
alkB & CUAAUUUAAUAAAUUGGAGAUUCCAUAUGCUUGAGAA \\
alkG & AACGCAAAAUAACAAUUUGACAUGUGAUGAGUAUGGCUA \\
Atf1 & CUAAUUUAAUAAAAUUGGAGAAUUCUGAAUGAACGAAAU \\
\hline
\end{tabular}

(b) pSEVAb658-B* ${ }^{*}{ }^{\top} \operatorname{TA}^{*}$

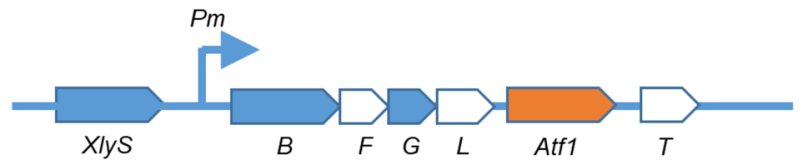

\begin{tabular}{ll}
\hline Gene & RNA sequence (NO Crc/Hfq binding site) \\
\hline alkB & CUAUACUAGAGAAAGAGGAGAAAUACUAGAUGCUUGAGAA \\
alkG & UUGCCGCUACUAGAGAAAGAGGAGAAAUACUAGAUGGCUA \\
Atf1 & UAAUACUAGAGAAAGAGGAGAAAUACUAGAUGAACGAAAU \\
\hline
\end{tabular}

Fig. 5 The schematic structure of plasmids (a) pBGTL-Atf1 and (b) pSEVAb658-B ${ }^{*} G^{*} T L-A t f 1{ }^{*}$. * represents removal of the Crc/Hfa mRNA attachment sites in the genes
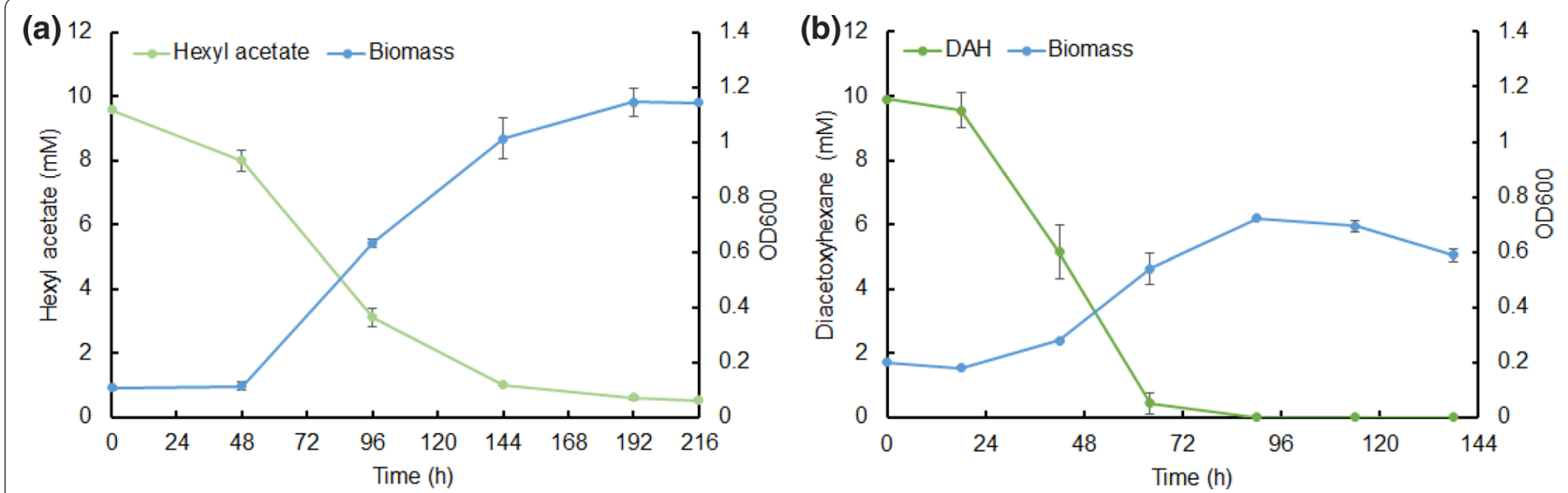

Fig. 6 Growth curves of P. putida KT2440 on $10 \mathrm{mM}$ a hexyl acetate and $\mathbf{b}$ diacetoxyhexane (DAH). Hexyl acetate or diacetoxyhexane was used as the only carbon source for cell growth. Each growth experiment was performed in triplicate

increase of 1.05. In the diacetoxyhexane case, the biomass concentration increased and the diacetoxyhexane concentration reduced over time (Fig. 6b). After a 24-h lag phase, the diacetoxyhexane concentration rapidly decreased until it was completely consumed at $72 \mathrm{~h}$. Nevertheless, the maximum optical density was only 0.72 with an $\mathrm{OD}_{600}$ increase of 0.52 , half of the OD increase of the hexyl acetate case. The difference between these two cases is that 1-hexanol was hydrolyzed from hexyl acetate and 1,6-hexanediol was obtained from diacetoxyhexane breakdown. According to Li et al. [30], 1,6-hexanediol cannot be utilized by the native metabolism of $P$. 
putida, while 1-hexanol can be easily assimilated. So in the diacetoxyhexane case, only the released acetate could be used as carbon source for cell growth. Therefore, a higher biomass concentration was obtained when hexyl acetate was fed. In summary, P. putida KT2440 is able to use hexyl acetate or diacetoxyhexane as the only carbon source to grow. We hypothesized that hydrolysis of hexyl acetate into 1-hexanol and acetate or hydrolysis of diacetoxyhexane into 1,6-hexanediol and acetate is the first and essential step for cell growth. Esterases are supposed to be responsible for this hydrolysis [32-34]. To prevent their action, we verified the presence and activity of relevant esterases.

\section{Screening of esterases in P. putida KT2440}

In $P$. putida KT2440, several esterase genes have been reported, such as EstZ and EstA [35]. However, it is unclear how many esterases were active in the above cases. To check for potential esterases, searches were performed based on the genome of $P$. putida KT2440 using the NCBI and CAZymes databases. As a result, 16 putative esterases were selected (Table 2).

To evaluate the performance of these 16 esterases, $E$. coli NEBT7 was used as a host for quick screening due to its relatively clear esterase background compared with P. putida KT2440. E. coli NEBT7 transformed with an empty pET26b plasmid was used as control strain. pET26b plasmids harboring the (putative) esterase genes were introduced into $E$. coli NEBT7. The transformed strains were used for monoester and diester hydrolysis.

Induced resting $E$. coli cells $\left(1 \mathrm{~g}_{\mathrm{cdw}} / \mathrm{L}\right)$ were fed with $20 \mathrm{mM}$ alkyl (C6-C10) acetate ester or diacetoxyhexane in tightly capped tubes. Production of mcl-n-alcohols (C6-C10), 6-hydroxy hexyl acetate and 1,6-hexanediol was used as an indicator to confirm esterase activity.
According to these criteria, three esterases (EstC, EstZ, Est12/K) were active in alkyl acetate ester hydrolysis (Fig. 7a). The rest of esterases showed no alcohol production (results not shown). Est12/K was always the best-performing esterase, no matter which alkyl acetate ester was fed. Of the 16 candidates seven esterases-Est1, EstB, EstC, EstP, EstZ, Est11, Est12/K-showed diacetoxyhexane hydrolysis activity, either to 6-hydroxy hexyl acetate or 1,6-hexanediol (Fig. 7b). Among these seven esterases, Est12/K showed the best hydrolysis performance producing $7.7 \mathrm{mM} \mathrm{1,6-hexanediol,} \mathrm{followed} \mathrm{by}$ EstB, EstC and Est11 exhibiting almost the same ability to hydrolyze diacetoxyhexane. Est1 only produced trace amounts of 6-hydroxy hexyl acetate and 1,6-hexanediol.

\section{Evaluation of the deletion of esterase in P. putida KT2440}

In the above analysis, esterases were highly expressed in E. coli. However, they might show different activity in $P$. putida KT2440 due to different expression levels of the esterase and diverse metabolism. To investigate their performance in $P$. putida, esterase knockout (KO) mutants were generated. Single $\mathrm{KO}$ and multiple $\mathrm{KO}$ mutants of EstB, EstC, EstP, EstZ and Est12/K in P. putida KT2440 were made and evaluated in hydrolysis tests. In addition to esterases, $\beta$-oxidation was assumed to be involved in consumption of alcohols from ester hydrolysis, facilitating this hydrolysis. Thus, key genes (FadA: acetyl-CoA acetyltransferase (PP_2137, PP_2215), FadB: 3-hydroxyacyl-CoA dehydrogenase/enoyl-CoA hydratase (PP_2047, PP_2136, PP_2214, PP_2217), FadE: acyl-CoA dehydrogenase (PP_2048, PP_2216) $[36,37]$ of $\beta$-oxidation were deleted, generating $P$. putida $\triangle \mathrm{BOX}$ as a control strain.

For alkyl acetate ester hydrolysis in $P$. putida and esterase $\mathrm{KO}$ mutants, hexyl acetate $(20 \mathrm{mM})$ was taken as example. The control strains, $P$. putida KT2440 and $P$.
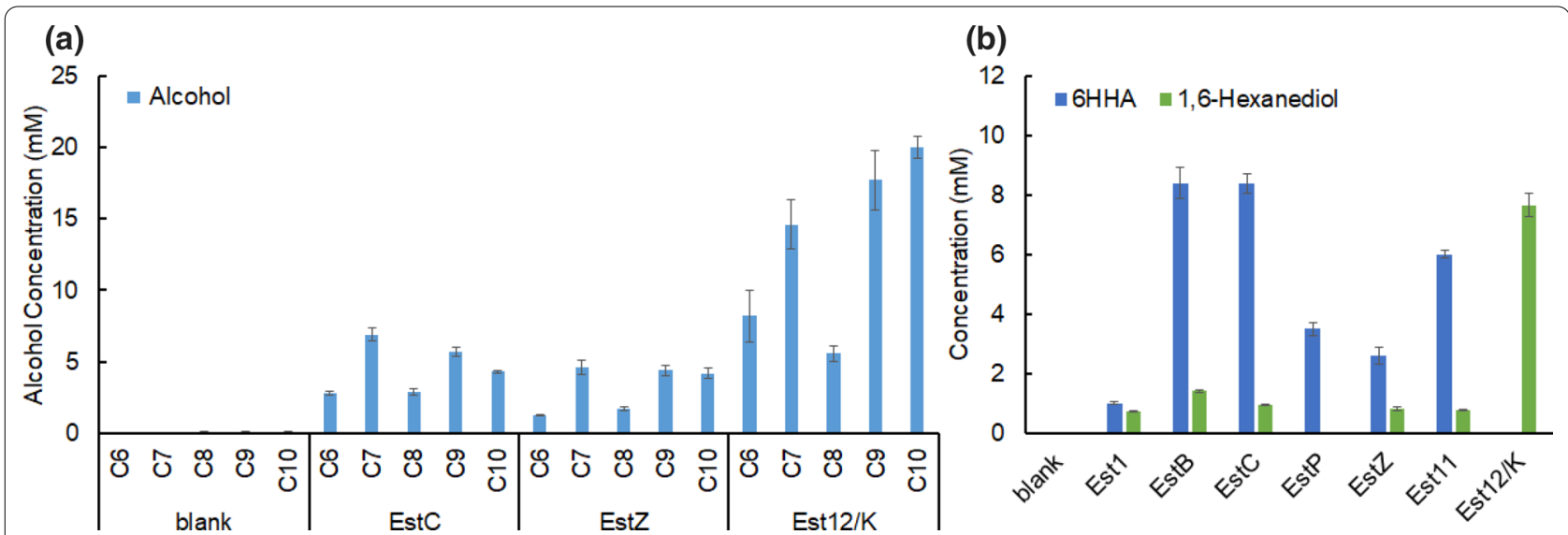

Fig. 7 Alkyl (C6-C10) acetate ester (a) and diacetoxyhexane (b) hydrolysis test by resting-cell of E. coli-pET26b-EstX in 20 h. EstX represents each putative esterase gene. Glucose was used to provide energy for cell maintenance. 6HHA: 6-hydroxy hexyl acetate 
putida $\triangle \mathrm{BOX}$, formed around $5.5 \mathrm{mM}$ 1-hexanol after $48 \mathrm{~h}$ of incubation (Fig. 8a). This shows that under the incubation conditions applied, $\beta$-oxidation did not play a significant role in alcohol consumption. The $\triangle$ EstBCPZ strain showed similar results, indicating that EstB, EstC, EstP and EstZ are not involved in hexyl acetate hydrolysis in P. putida cultivated under these conditions. When Est $12 / K$ was deleted, 1-hexanol was not detected anymore. For diacetoxyhexane hydrolysis, the data showed a similar trend (Fig. 8b). The intermediate ester, 6-hydroxy hexyl acetate, the product of a single hydrolysis, was not observed. In brief, Est12/K is the most dominant esterase responsible for the breakdown of alkyl acetate and diacetoxyhexane in P. putida KT2440.

\section{Diacetoxyhexane production in engineered $P$. putida KT2440}

In the next step, we combined the esterase knockout strain with the expression of Crc-independent AlkBGTL-Atf1. pSEVA658-B"G"TL-Atf1" was transferred to P. putida $\Delta$ Est $12 / \mathrm{K}$ giving rise to $\Delta \mathrm{Est} 12 / \mathrm{K}-\mathrm{B}^{*} \mathrm{G}^{\prime T} \mathrm{TLA}$ ". When $\mathrm{n}$-hexane was used as substrate in resting-cell suspension of strain $\Delta$ Est12/K-B"G"TLA", $0.4 \mathrm{mM}$ hexanol and $3.7 \mathrm{mM}$ hexyl acetate were produced. The production of hexyl acetate was increased by 12.7 -fold compared with that of P-BGTLA. This mainly resulted from the deletion of Est $12 / K$, preventing the hydrolysis of hexyl acetate. Besides, optimized AlkBGTL also provides more hexanol for hexyl acetate formation. However, 6-hydroxy hexyl acetate and 1,6-diacetoxyhexane were still not detected (data not shown). In a similar setup, using hexyl acetate as substrate, $\Delta$ Est12/K-B"G"TLA" produced $6.9 \mathrm{mM}$ total products (Fig. 9b). Compared with P-B"G"TLA", $\triangle$ Est12/K-B"G"TLA" produced 1.1-fold more total products. The production of 6-hydroxy hexyl acetate increased by 3.8-fold, indicating that 6-hydroxy hexyl acetate might be hydrolyzed when Est $12 / \mathrm{K}$ is present. In the end, the total amount of products was increased by 4.2 -fold in $\triangle$ Est $12 / \mathrm{K}-\mathrm{B}^{\prime \prime G}$ "TLA" compared with the starting strain P-BGTLA. $11.5 \%$ of the substrate (hexyl acetate) was $\omega$-oxidized by $\Delta$ Est12/K-B"G"TLA", 4.2-fold of that of P-BGTLA.

Both interventions, preventing hydrolysis of esters and uncoupling ester production from carbon catabolite repression, resulted in improved ester production. However, ester production is still lower in P. putida compared with that in E. coli. There are three main differences between the two hosts for ester synthesis. First, in a similar setup $E$. coli showed a threefold higher production rate when hexane was used as starting substrate [19]. The lower production rate of $P$. putida may be attributed to the availability of NADH-required for AlkBGT activity-and acetyl-CoA-required for Atf1 activity. Whereas E. coli's dissimilation is based on NADH, $P$. putida's dissimilation has a stronger focus on $\mathrm{NADP}^{+}$reduction, mediated by the ED-EMP pathway [38]. Although this is generally an advantage in $P$. putida with regard to its metabolic prowess, in this specific case, this may have resulted in a low availability of NADH and hence a lower AlkBGT activity. Glucose was added to provide the acetyl-CoA. However, when glucose was fed to P. putida, the majority of glucose is not directly assimilated but is channelled to periplasmic gluconate and 2-ketogluconate pathways, and secreted in the presence of abundant
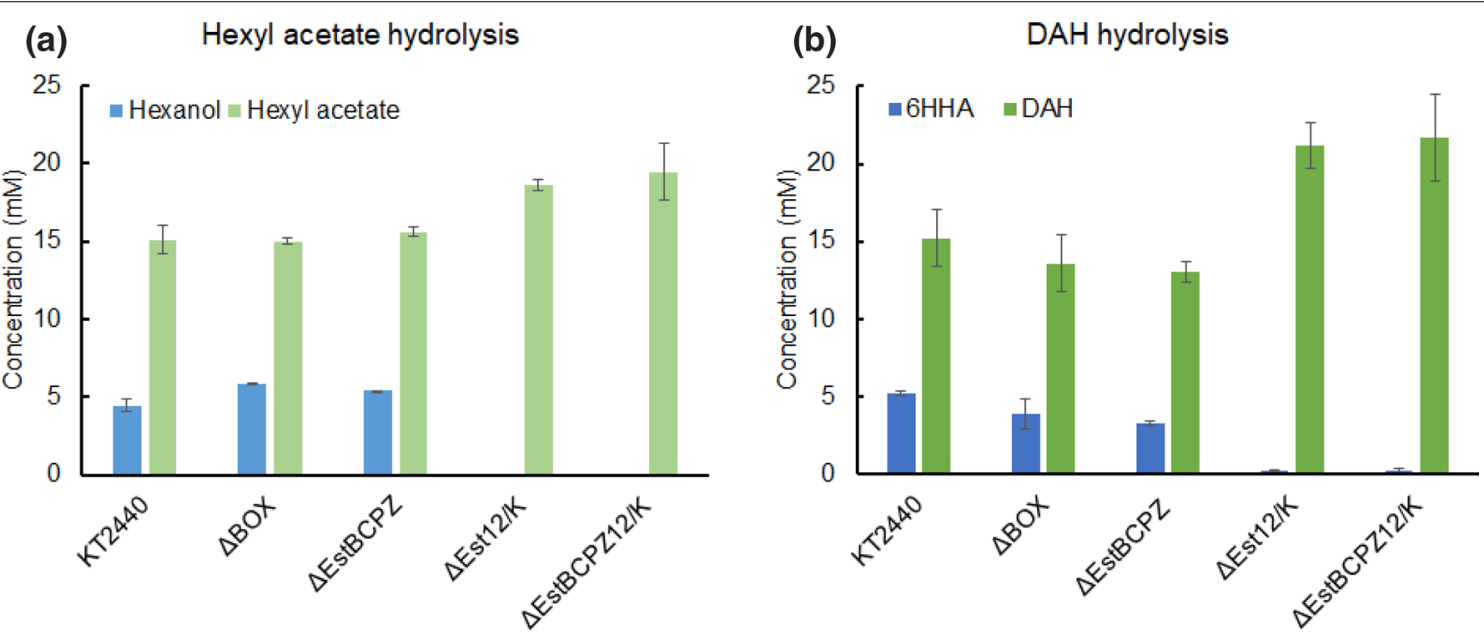

Fig. 8 Esterase deletion mutants of P. putida KT2440 for a $20 \mathrm{mM}$ hexyl acetate hydrolysis test in $48 \mathrm{~h}$ and $\mathbf{b} 20 \mathrm{mM}$ diacetoxyhexane hydrolysis test

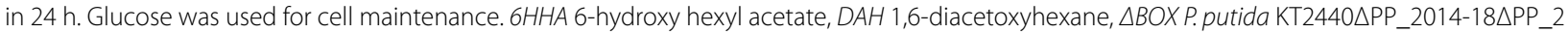

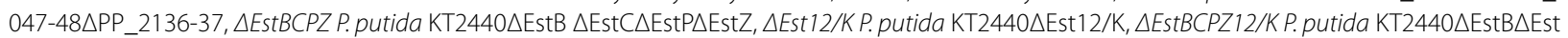
C $\triangle$ EstP $\triangle$ EstZ $\triangle$ Est12/K 


\section{(a)}

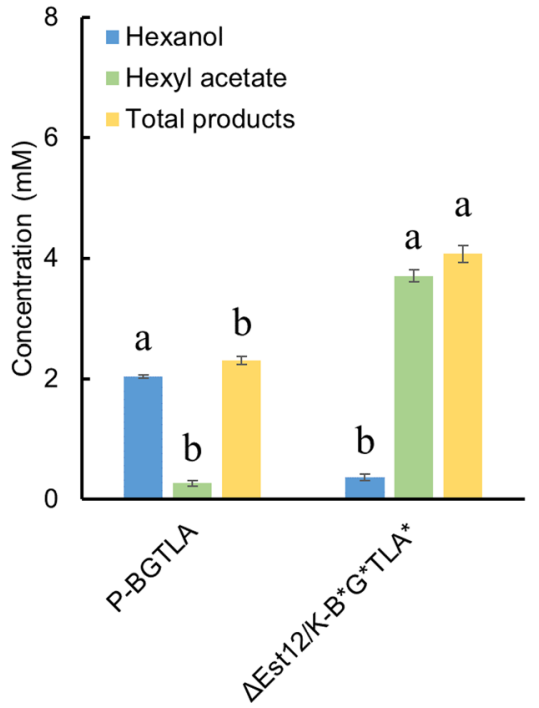

(b)

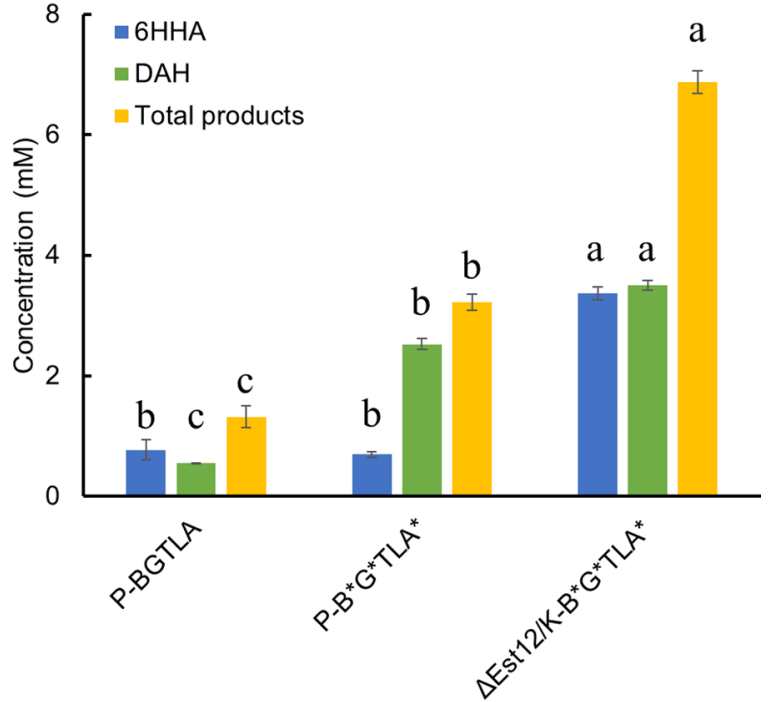

Fig. 9 Oxidation conversion of $n$-hexane and hexyl acetate by engineered strains under resting-cell conditions. a Hexyl acetate production from $1 \% \mathrm{v} / \mathrm{v} \mathrm{n}$-hexane in engineered $P$. putida KT2440. b DAH production from $1 \% \mathrm{v} / \mathrm{v}$ hexyl acetate in engineered $P$. putida KT2440. Glucose was fed for cell maintenance. 6HHA 6-hydroxy hexyl acetate, DAH 1,6-diacetoxyhexane, P-BGTLA P. putida KT2440 with alkBGTL-Atf1 expression, $P$ - $B^{*} G^{*} T L A^{*} P$. putida KT2440 with expression of alkBGTL-Atf1 where the Crc/Hfq mRNA attachment sites of alkB, alkG and Atf1 were removed, $\triangle E s t 12 / K-B^{*} G^{*} T L A^{*}$ P. putida KT2440 $\triangle$ Est12/K expression of alkBGTL-Atf1 where the Crc/Hfq mRNA attachment sites of alkB, alkG and Atf1 were removed. Bars with different letters indicate significant difference from each other (comparisons were implemented among bars with the same color) $(p<0.05)$

glucose [39], limiting the supply of acetyl-CoA. In addition, glucose is the preferred substrate for $E$. coli, but not for $P$. putida [10]. The conversion of hexane results in the accumulation and excretion of many intermediate molecules. Some of these molecules may be preferred as substrate over glucose, resulting in a lower availability of acetyl-CoA and hence a lower Atf1 activity. The same reasoning, based on the difference in substrate preference between $E$. coli and P. putida may also be applied to the second difference found. In E. coli AlkBGT overoxidizes a part of the hexanol into hexanoic acid. Esterification of hexanol and 6-hydroxy hexyl acetate with acetyl-CoA mediated by Atf1 was not able to prevent this completely. None of hexanoic acid, 6-hydroxyhexanoate, and adipic acid were observed as byproduct using $P$. putida. This can however not be attributed to a high activity of Atf1, because both hexanol and 6-hydroxy hexyl acetate accumulated. It seems more likely that overoxidation did occur, but that the overoxidized product hexanoic acid was possibly preferred as substrate over glucose and hexane. The third difference is that in E. coli hexane can be directly converted into diacetoxyhexane. This direct conversion does not occur in P. putida, although it is able to convert hexane into hexyl acetate and added hexyl acetate in diacetoxyhexane. The ability of AlkBGT to oxidize both hexane and hexyl acetate simultaneously in E. coli and not in P. putida suggests that in the latter microorganism the ratio of intracellular concentrations of hexane and hexyl acetate is larger, favoring hexane oxidation by substrate competition.

\section{Conclusions}

P. putida KT2440 is known for its robustness, versatile metabolism and high oxidative capacity, all of which render it a preferred platform for a range of industrial applications $[6-8,40,41]$. This study shows that this metabolic prowess also has its down side. We found that metabolic versatility and associated carbon catabolite repression hinder oxyfunctionalization of alkanes by alkBGTL-Atf1 in P. putida KT2440. Both could be overcome by 1) deleting the committed step of diacetoxy alkane degradation performed by esterase Est12/K and 2) by deleting the $\mathrm{Crc} / \mathrm{Hfq}$ attachment site of relevant genes involved in oxyfunctionalization to avoid catabolite repression. Nevertheless, the realized level of diacetoxy alkane production is still low, and more research is required to make the process industrially applicable.

Although the role of catabolite repression in direct product formation was diminished, the results also indicate that the formed (by)products may still affect other parts of the metabolic network by carbon catabolite repression. Biotechnological process development is largely about engineering the most (cost-)effective conversion of a chosen substrate into a chosen product. The 
substrate preference of $P$. putida may conflict with these choices, if the product is preferred as substrate. This phenomenon is already known as the Kluyver effect for some yeasts, which are not able to convert some disaccharides into ethanol, because ethanol is preferred as substrate [42]. Sugars are often the main substrates used in biotechnological processes. Sugars are, however, not the preferred substrates of $P$. putida. This ultimately hampers the ability to use $P$. putida for the production of certain compounds, e.g. organic acids and amino acids. The strategy we used to delete mRNA $\mathrm{Crc} / \mathrm{Hfq}$ attachment sites may alleviate this when applied to genes involved in sugar catabolism for other applications. Moreover, the ability to regulate many enzyme activities at the same time with $\mathrm{Crc} / \mathrm{Hfq}$, as long as the genes involved contain an (introduced) mRNA attachment site, could be a promising tool in metabolic engineering.

\section{Materials and methods}

\section{Strains, plasmids and medium}

Strains and plasmids used in this study are listed in Table 1. E. coli $5 \alpha$ was used for cloning purposes. E. coli NEBT7 was used for ester hydrolysis tests. The construction of plasmids is described in the supplementary file. $P$. putida KT2440 as the parental strain was engineered for different study aims. According to Nicolas and Daniel's method [43], a suicide plasmid pGNW2 and a self-curing plasmid pQURE6 $\cdot \mathrm{H}$ bearing the I-SceI gene were used to delete genes in $P$. putida KT2440. The M9 medium consisted of $1 \times \mathrm{M} 9$ minimal salts, $0.2 \mathrm{mM} \mathrm{MgSO}_{4} \cdot 7 \mathrm{H}_{2} \mathrm{O}$, $55 \mathrm{mM}$ glucose and $1 \mathrm{~mL} / \mathrm{L}$ trace elements $\mathrm{US}^{\mathrm{Fe}}$ [44]. $\mathrm{M} 9^{\mathrm{E}}$ medium was used for cell preculture and induction of genes of interest. It consisted of M9 medium, $0.1 \mathrm{mM}$ $\mathrm{CaCl}_{2} \cdot 2 \mathrm{H}_{2} \mathrm{O}, 100 \mathrm{mM} 3-(\mathrm{N}$-morpholino) propanesulfonic acid sodium salt buffer (MOPS), and $1 \mathrm{~mL} / \mathrm{L} 1000 \times$ vitamins [45]. The media were adjusted to $\mathrm{pH} 7.0$ with $1 \mathrm{M}$ hydrochloric acid or sodium hydroxide and subsequently filter-sterilized using a $0.22 \mu \mathrm{m}$ Nalgene ${ }^{\circledR}$ polyethersulfone (PES) filter (ThermoFisher). Kanamycin (Km) and gentamicin $(\mathrm{Gm})$ were separately added at $50 \mu \mathrm{g} / \mathrm{mL}$ and $10 \mu \mathrm{g} / \mathrm{mL}$, respectively, when needed.

\section{Cultivation and gene expression}

Strains harboring plasmids pCOM_alkL, pBTL10 or pBGTL-Atf1 were inoculated in LB overnight. The overnight culture $(1 \% \mathrm{v} / \mathrm{v})$ was used to inoculate M9 medium and cultured overnight again. $\mathrm{OD}_{600}$ was always determined spectrophotometrically with $4 \mathrm{~mm}$ cuvette. The day after, this overnight culture was used to inoculate $50 \mathrm{~mL}$ of M9 medium at an initial $\mathrm{OD}_{600}$ of 0.25 , induced by $0.025 \% \mathrm{v} / \mathrm{v}$ dicyclopropylketone (DCPK) for gene expression. After 5 -h induction at $30^{\circ} \mathrm{C}$ and $250 \mathrm{rpm}$ agitation in a Kuhner shaker incubator, cells were harvested by centrifugation at $4200 \times g$ for $10 \mathrm{~min}$. Cell pellets were suspended at $1 \mathrm{~g}_{\mathrm{cdw}} / \mathrm{L}$ in resting cell buffer, containing $50 \mathrm{mM} \mathrm{KPi} \mathrm{pH} \mathrm{7.4,} 2 \mathrm{mM} \mathrm{MgSO}_{4}$, and 1\% v/v glucose. Strains harboring pSEVAb plasmids were cultivated under the same conditions as described above [46, 47], except for induction with $1 \mathrm{mM} 3$-methylbenzoate.

\section{Ester hydrolase screening and strain construction for tests}

For the ester hydrolase screening, two main databases, NCBI and the Carbohydrate-Active enZYmes [48, 49], were used to search putative hydrolase-like esterase or lipase in P. putida KT2440. Each putative ester hydrolase gene $(E s t X)$ with a Strep-tag II at the C-terminal end was inserted into a pET26b plasmid to generate pET26b-EstX by HiFi assembly. All primers for these constructions are listed in Table S1. E. coli NEBT7 was transformed with the pET26b-EstX to give rise to E. coli-EstX for ester hydrolysis tests.

\section{Resting-cell hydrolysis assay}

E. coli-EstX was inoculated in LB medium and grown overnight. An aliquot of the overnight culture $(300 \mu \mathrm{L})$ was inoculated in $30 \mathrm{~mL} \mathrm{M} 9^{\mathrm{E}}$ medium and grown overnight. This culture was used to inoculate $50 \mathrm{~mL} \mathrm{M9}$ medium at an initial $\mathrm{OD}_{600}$ of 0.15 . After $5 \mathrm{~h}$ of cultivation $\left(\mathrm{OD}_{600}=0.6-0.8\right), 0.1 \mathrm{mM}$ isopropyl $\beta-\mathrm{D}-1$ thiogalactopyranoside (IPTG) was added to induce ester hydrolase gene expression at $25^{\circ} \mathrm{C}$, at $250 \mathrm{rpm}$ agitation in a Kuhner incubator for $16 \mathrm{~h}$. Once induction finished, the cells were harvested by centrifugation at $4200 \times \mathrm{g}$.

Cell pellets were suspended in the resting-cell buffer to a density of $1 \mathrm{~g}_{\mathrm{cdw}} / \mathrm{L}$. Aliquots of $1 \mathrm{~mL}$ resting cells were taken for each reaction in a Pyrex tube. Alkyl (C6-C10) acetate and diacetoxyhexane $(20 \mathrm{mM})$ were added to each tube, and then the tube was cultivated for $20 \mathrm{~h}$ at $30{ }^{\circ} \mathrm{C}, 250 \mathrm{rpm}$. All reactions were performed in triplicate. Afterwards, $1 \% \mathrm{v} / \mathrm{v}$ of phosphoric acid was immediately added to stop reactions and all tubes were placed on ice. Samples were extracted by diethyl ether with $0.2 \mathrm{mM}$ dodecane as an internal standard for GC analysis.

\section{Growth test on hexyl acetate and diacetoxyhexane medium}

P. putida KT2440 was cultivated in LB overnight. The overnight culture $(1 \% \mathrm{v} / \mathrm{v})$ was used to inoculate $50 \mathrm{~mL}$ M9 medium in a $250-\mathrm{mL}$ shake flask and cultivated overnight again. The day after, this overnight culture was used to inoculate $10 \mathrm{~mL} \mathrm{M9} \mathrm{medium} \mathrm{in} 50-\mathrm{mL}$ tubes $(10 \mathrm{mM}$ hexyl acetate or diacetoxyhexane as the only carbon source) with an initial $\mathrm{OD}_{600}$ of 0.15 . Three tubes were taken out every $24 \mathrm{~h}$ for optical density and substrate concentration assays. Samples for GC analysis were prepared as mentioned above. 
Table 1 Plasmids and strains used in this work

\begin{tabular}{|c|c|c|}
\hline Name & Description & References \\
\hline \multicolumn{3}{|l|}{ Plasmids } \\
\hline pCOM_AlkL & pCOM10 vector containing AlkL gene; $\mathrm{Km}^{\mathrm{R}}$ & [22] \\
\hline pBTL10 & pCOM10 vector containing AlkBGTL genes; $\mathrm{Km}^{\mathrm{R}}$ & [50] \\
\hline pBGTL-Atf1 & pCOM10 vector containing AlkBGTL-Atf1 genes; $\mathrm{Km}^{\mathrm{R}}$ & [19] \\
\hline pSEVAb628 & Expression vector; oriV(RK2); XyIS, Pm; Gm & [47] \\
\hline pSEVAb658 & Expression vector; oriV(RSF1010); XyIS, Pm; Gm ${ }^{R}$ & [47] \\
\hline pSEVAb628-AlkS & pSEVAb628 vector containing $P m \rightarrow A l k S ; \mathrm{Gm}^{\mathrm{R}}$ & This work \\
\hline pSEVAb658-B* $G^{*} T L A^{*}$ & pSEVAb658 vector containing $P m \rightarrow A l k B^{*} G^{*} T L-A t f 1^{*} ; G^{R}$ & This work \\
\hline pET26b-EstX & pET26b vector containing $T 7 \rightarrow$ Est $X, X$ represents each putative esterase gene; $\mathrm{Km}^{\mathrm{R}}$ & This work \\
\hline pGNW2 & $\begin{array}{l}\text { Suicide vector used for gene deletion in P. putida KT2440; oriV(R6K) containing P14g } \rightarrow \text { msfGFP; } \\
\mathrm{Km}^{R}\end{array}$ & [43] \\
\hline $\mathrm{pGNW} 2-\triangle \mathrm{Crc}$ & Derivative of vector pGNW2 containing HRs to delete CrC (PP_5292) & This work \\
\hline pGNW2- $\triangle$ CyoB & Derivative of vector pGNW2 containing HRs to delete CyoB (PP_0813) & This work \\
\hline pGNW2- $\triangle$ EstX & Derivative of vector pGNW2 containing HRs to delete EsteraseX (Table 2) & This work \\
\hline pGNW2-PP_2047-48 & Derivative of vector pGNW2 containing HRs to delete PP_2047-48 & This work \\
\hline pGNW2-PP_2136-37 & Derivative of vector pGNW2 containing HRs to delete PP_2136-37 & This work \\
\hline pGNW2-PP_2214-18 & Derivative of vector pGNW2 containing HRs to delete PP_2214-18 & This work \\
\hline \multicolumn{3}{|l|}{ Strains } \\
\hline P. putida KT2440 & Wild-type strain, derived from P. putida mt-2[51] & {$[52]$} \\
\hline$\Delta \mathrm{CrC}$ & P. putida KT2440 $\triangle$ Crc & This work \\
\hline$\triangle \mathrm{CyoB}$ & P. putida KT2440 $\triangle$ CyoB & This work \\
\hline$\Delta \mathrm{Crc} \Delta \mathrm{CyoB}$ & P. putida KT2440 $\triangle \mathrm{Cr} C \triangle C y o B$ & This work \\
\hline$\triangle \mathrm{EstBCPZ}$ & P. putida KT2440 $\triangle E s t B C P Z$ & This work \\
\hline$\Delta$ Est12/K & P. putida KT2440 $\triangle$ Est12/K & This work \\
\hline$\triangle \mathrm{EstBCPZ12/K}$ & P. putida KT2440 $\triangle E s t B C P Z \triangle E s t 12 / K$ & This work \\
\hline P. putida $\triangle \mathrm{BOX}$ & P.putida KT2440 $P P P \_2047-48 \triangle P P \_2136-37 \triangle P P \_2214-18$ & This work \\
\hline P-L & P.putida KT2440 harboring pCOM_alkL & This work \\
\hline P-BGTL & P. putida KT2440 harboring pBTL10 & This work \\
\hline P-BGTLA & P. putida KT2440 harboring pBGTL-Atf1 & This work \\
\hline$\triangle \mathrm{CrC}-\mathrm{BGTL}$ & P. putida KT2440 $\triangle$ Crc harboring pBTL10 & This work \\
\hline$\triangle C$ CyoB-BGTL & P. putida KT2440 $\triangle$ CyoB harboring pBTL10 & This work \\
\hline$\Delta \mathrm{Crc} \Delta \mathrm{CyoB}-\mathrm{BGTL}$ & P. putida KT2440 $\triangle \mathrm{Crc} \triangle \mathrm{CyoB}$ harboring pBTL10 & This work \\
\hline$\triangle \mathrm{CrC}-\mathrm{BGTLA}$ & P. putida KT2440 $\triangle$ Crc harboring pBGTL-Atf1 & This work \\
\hline$\triangle C$ CyoB-BGTLA & P. putida KT2440 $\triangle$ CyoB harboring pBGTL-Atf1 & This work \\
\hline$\triangle \mathrm{CrC}-\mathrm{BGTLAS}$ & P. putida KT2440 $\triangle$ Crc harboring pBGTL-Atf1, and pSEVAb628-alkS & This work \\
\hline$\triangle$ CyoB-BGTLAS & P. putida KT2440 $\triangle$ CyoB harboring pBGTL-Atf1, and pSEVAb628-alkS & This work \\
\hline$P-B^{*} G^{*} T L A^{*}$ & P. putida KT2440 harboring pSEVAb658-B* $G^{*} T L A^{*}$ & This work \\
\hline$\triangle$ Est $12 / K-B^{*} G^{*} T L A^{*}$ & P. putida KT2440 $\triangle$ Est12/K harboring pSEVAb658-B* $G^{*} T L A^{*}$ & This work \\
\hline E. coli blank & E. coli NEBT7 harboring pET26b & This work \\
\hline E. coli-EstX & E. coli NEBT7 harboring pET26b-EstX & This work \\
\hline
\end{tabular}

$H R s=$ homologous regions

*Represents removal of $\mathrm{Crc} / \mathrm{Hfq}$ mRNA attachment sites in the gene 
Table 2 Putative esterases found in P. putida KT2440

\begin{tabular}{lllll}
\hline $\begin{array}{l}\text { Esterase } \\
\text { name }\end{array}$ & Protein ID & $\begin{array}{l}\text { Accession } \\
\text { No. }\end{array}$ & Locus tag & Gene size (bp) \\
\hline Est1 & AAN65995.1 & Q88QX0 & PP_0364 & 732 \\
EstB & AAN66920.1 & Q88NB6 & PP_1296 & 657 \\
EstC & AAN66752.1 & Q88NS7 & PP_1127 & 1146 \\
EstP & AAN66048.1 & Q88QS0 & PP_0418 & 1890 \\
Est5 & AAN67115.1 & Q88MS5 & PP_1493 & 1014 \\
Est6 & AAN69353.1 & Q88GG5 & PP_3759 & 576 \\
EstZ & AAN69799.1 & Q88F80 & PP_4218 & 957 \\
Est8 & AAN69916.1 & Q88EW5 & PP_4337 & 1113 \\
Est9 & AAN70088.2 & Q88EF1 & PP_4514 & 2187 \\
Est10 & AAN70483.2 & Q88DB1 & PP_4916 & 609 \\
Est11 & AAN67697.1 & Q88L52 & PP_2083 & 1029 \\
Est12/K & AAN69406.1 & Q88GB2 & PP_3812 & 1020 \\
Est13 & AAN70423.1 & Q88DH1 & PP_4854 & 891 \\
Est14 & AAN66966.1 & Q88N71 & PP_1343 & 912 \\
Est15 & AAN69866.1 & Q88F13 & PP_4286 & 927 \\
Est16 & AAN68665.1 & Q88IE2 & PP_3057 & 741 \\
\hline
\end{tabular}

\section{HPLC analysis}

HPLC analysis was conducted with an Agilent 1260 Infinity UPLC with a $30 \mathrm{~cm}$ Rezex ROA column (Phenomenex), run at a flowrate of $0.8 \mathrm{~mL} / \mathrm{min}$ with $5 \mathrm{mM}$ $\mathrm{H}_{2} \mathrm{SO}_{4}$ as mobile phase and column temperature of at $25{ }^{\circ} \mathrm{C}$. Quantitative analysis of metabolites was performed using a refractive index detector (RID).

\section{GC analysis}

GC analysis was carried out on an Agilent 7890A gas chromatograph equipped with a flame ionization detector (FID) using the HP-5 column $(30 \mathrm{~m} \times 30 \mu \mathrm{m} \times 0.25 \mu \mathrm{m})$. $1 \mu \mathrm{L}$ sample was injected in splitless mode, using the following temperature program: $50{ }^{\circ} \mathrm{C}$ for $3 \mathrm{~min}, 15^{\circ} \mathrm{C} / \mathrm{min}$ increase to $180{ }^{\circ} \mathrm{C}, 7{ }^{\circ} \mathrm{C} / \mathrm{min}$ increase to $230{ }^{\circ} \mathrm{C}, 30{ }^{\circ} \mathrm{C} /$ min increase to $350^{\circ} \mathrm{C}$, which was held for $3 \mathrm{~min}$. Quantification was done by using available standards. If standards were not commercially available, quantification was done on the basis of structurally related compounds with similar numbers of carbon/hydrogen atoms. For example, mono-hexyl adipate was quantified based on mono-ethyl sebacate.

\footnotetext{
Abbreviations

Mcl-diols: Medium-chain-length a,w-diols; CCR: Carbon catabolite repression; AlkS: Activator of alkane degradation pathway; Crc: Global regulator of carbon catabolite repression; Cyo: Cytochrome o ubiquinol oxidase; B: AlkB, Alkane monooxygenase; F: AlkF, rubredoxin which is indispensable for AlkB activity; G: AlkG, rubredoxin; L: AlkL, outer membrane protein; T: AlkT, rubredoxin reductase; S: AlkS, activator of alkane degradation pathway; PalkS2: Promoter of AlkS with efficient transcription in presence of alkanes; PalkS1: Promoter of AlkS in absence of alkanes; PalkB: Promoter of AlkB; CyoB: The key gene of cytochrome o ubiquinol oxidase; Atf1: Alcohol acetyltransferase; EST: Esterases;
}

ADH: Alcohol dehydrogenase; ALDH: Aldehyde dehydrogenase; ALR: Aldehyde reductase; CAR: Carboxylic acid reductase; PPT: Phosphopantetheinyl transferase; 6HHA: 6-Hydroxy hexyl acetate; DAH: 1,6-Diacetoxyhexane; Glc: Glucose; Cit: Citrate; KO: Knockout; BOX: Beta-oxidation; FadA: Acetyl-CoA acetyltransferase; FadB: 3-Hydroxyacyl-CoA dehydrogenase/enoyl-CoA hydratase; FadE: Acyl-CoA dehydrogenase; PES: Polyethersulfone; Km: Kanamycin; Gm: Gentamicin; DCPK: Dicyclopropylketone; EstX: Putative ester hydrolase gene; IPTG: Isopropyl $\beta$-D-1-thiogalactopyranoside; RID: Refractive index detector; FID: Flame ionization detector.

\section{Supplementary Information}

The online version contains supplementary material available at https://doi. org/10.1186/s13068-021-02066-x.

Additional file 1: Table S1. Primers used in this study.

\section{Acknowledgements}

We thank Dr. Pablo I. Nikel (DTU Biosustain) for donating the plasmid pQURE.H6. This work was supported by a Chinese Scholarship Council stipend (to C. Lu).

\section{Authors' contributions}

All authors designed the work. CL and EA conducted, analysed and interpreted the experiments. CL drafted and wrote the manuscript. All authors read and approved the final manuscript.

\section{Funding}

Not applicable.

\section{Availability of data and materials}

All data generated or analysed during this study are included in this published article and its additional information files.

\section{Declarations}

Ethics approval and consent to participate

Not applicable.

Consent for publication

Not applicable.

\section{Competing interests}

The authors declare that they have no competing interests.

\section{Author details}

${ }^{1}$ Bioprocess Engineering, Wageningen University and Research, Wageningen, The Netherlands. ${ }^{2}$ Laboratory of Systems and Synthetic Biology, Wageningen University and Research, Wageningen, The Netherlands. ${ }^{3}$ Lifeglimmer GmbH, Berlin, Germany. ${ }^{4}$ Faculty of Biosciences and Aquaculture, Nord University, Bodø, Norway.

Received: 10 August 2021 Accepted: 6 November 2021

Published online: 20 November 2021

\section{References}

1. Mohamed ET, Werner AZ, Salvachúa D, Singer CA, Szostkiewicz K, Rafael Jiménez-Díaz M, et al. Adaptive laboratory evolution of Pseudomonas putida KT2440 improves p-coumaric and ferulic acid catabolism and tolerance. Metab Eng Commun. 2020;11:e00143.

2. Prieto A, Escapa IF, Martínez V, Dinjaski N, Herencias C, de la Peña F, et al. A holistic view of polyhydroxyalkanoate metabolism in Pseudomonas putida. Environ Microbiol. 2016;18:341-57.

3. Martin-Pascual M, Batianis C, Bruinsma L, Asin-Garcia E, Garcia-Morales $L$, Weusthuis RA, et al. A navigation guide of synthetic biology tools for Pseudomonas putida. Biotechnol Adv. 2021;49:107732. 
4. Becker J, dos Santos VM, Wittmann C, Dohnt K, Poblete-Castro I. Industrial biotechnology of Pseudomonas putida and related species. Appl Microbiol Biotechnol. 2012;93:2279-90.

5. Martins Dos Santos VAP, Heim S, Moore ERB, Strätz M, Timmis KN. Insights into the genomic basis of niche specificity of Pseudomonas putida KT2440. Environ Microbiol. 2004;6:1264-86.

6. Belda E, van Heck RGA, José Lopez-Sanchez M, Cruveiller S, Barbe V, Fraser C, et al. The revisited genome of Pseudomonas putida KT2440 enlightens its value as a robust metabolic chassis. Environ Microbiol. 2016;18:3403-24.

7. Puchałka J, Oberhardt MA, Godinho M, Bielecka A, Regenhardt D, Timmis KN, et al. Genome-scale reconstruction and analysis of the Pseudomonas putida KT2440 metabolic network facilitates applications in biotechnology. PLoS Comput Biol. 2008;4:e1000210.

8. Nikel PI, de Lorenzo V. Pseudomonas putida as a functional chassis for industrial biocatalysis: from native biochemistry to trans-metabolism. Metab Eng. 2018;50:142-55.

9. Moreno R, Marzi S, Romby P, Rojo F. The Crc global regulator binds to an unpaired A-rich motif at the Pseudomonas putida alkS mRNA coding sequence and inhibits translation initiation. Nucleic Acids Res. 2009;37:7678-90.

10. Rojo F. Carbon catabolite repression in Pseudomonas: optimizing metabolic versatility and interactions with the environment. FEMS Microbiol Rev. 2010;34:658-84.

11. Dinamarca MA, Ruiz-Manzano A, Rojo F. Inactivation of cytochrome o ubiquinol oxidase relieves catabolic repression of the Pseudomonas putida GPo1 alkane degradation pathway. J Bacteriol. 2002;184:3785-93.

12. Kawaguchi $\mathrm{H}$, Ogino $\mathrm{C}$, Kondo A. Microbial conversion of biomass into bio-based polymers. Bioresour Technol. 2017;245:1664-73.

13. Lligadas G, Ronda JC, Galià M, Cádiz V. Oleic and undecylenic acids as renewable feedstocks in the synthesis of polyols and polyurethanes. Polymers (Basel). 2010;2:440-53.

14. Youngquist JT, Schumacher MH, Rose JP, Raines TC, Politz MC, Copeland MF, et al. Production of medium chain length fatty alcohols from glucose in Escherichia coli. Metab Eng. 2013;20:177-86.

15. Kruis AJ, Bohnenkamp AC, Patinios C, van Nuland YM, Levisson M, Mars AE, et al. Microbial production of short and medium chain esters: Enzymes, pathways, and applications. Biotechnol Adv. 2019;37:107407.

16. Li X, Luo J, Liang C. Hydrogenation of adipic acid to 1,6-hexanediol by supported bimetallic Ir-Re catalyst. Mol Catal. 2020;490:110976.

17. Hsieh S, Wang J, Lai Y, Su C, Lee K. Production of 1-dodecanol, 1-tetradecanol, and 1,12-dodecanediol through whole-cell biotransformation in Escherichia coli. Appl Environ Microbiol. 2018;84:1-12.

18. Ahsan MM, Sung S, Jeon H, Patil MD, Chung T, Yun H. Biosynthesis of medium- to long-chain $a, \omega$-diols from free fatty acids using CYP153A monooxygenase, carboxylic acid reductase, and E. coli endogenous aldehyde reductases. Catalysts. 2018;8:1-11.

19. van Nuland YM, de Vogel FA, Scott EL, Eggink G, Weusthuis RA. Biocatalytic, one-pot diterminal oxidation and esterification of $n$-alkanes for production of $a, \omega$-diol and a, $\omega$-dicarboxylic acid esters. Metab Eng. 2017:44:134-42.

20. Canosa I, Sánchez-Romero JM, Yuste L, Rojo F. A positive feedback mechanism controls expression of AlkS, the transcriptional regulator of the Pseudomonas oleovorans alkane degradation pathway. Mol Microbiol. 2000:35:791-9.

21. Yoo HW, Kim J, Patil MD, Park BG, Joo SY, Yun H, et al. Production of 12-hydroxy dodecanoic acid methyl ester using a signal peptide sequence-optimized transporter AlkL and a novel monooxygenase. Bioresour Technol. 2019;291:121812.

22. Julsing MK, Schrewe M, Cornelissen S, Hermann I, Schmid A, Bühler B. Outer membrane protein alkL boosts biocatalytic oxyfunctionalization of hydrophobic substrates in Escherichia coli. Appl Environ Microbiol. 2012;78:5724-33.

23. Bharwad K, Rajkumar S. Rewiring the functional complexity between Crc, $\mathrm{Hfq}$ and sRNAs to regulate carbon catabolite repression in Pseudomonas. World J Microbiol Biotechnol. 2019;35:1-12.

24. Yuste L, Rojo F. Role of the crc gene in catabolic repression of the Pseudomonas putida GPo1 alkane degradation pathway. J Bacteriol. 2001;183:6197-206.

25. Hernández-Arranz S, Moreno R, Rojo F. The translational repressor Crc controls the Pseudomonas putida benzoate and alkane catabolic pathways using a multi-tier regulation strategy. Environ Microbiol. 2013;15(1):227-41.

26. Sevilla E, Silva-Jiménez H, Duque E, Krell T, Rojo F. The Pseudomonas putida HskA hybrid sensor kinase controls the composition of the electron transport chain. Environ Microbiol Rep. 2013;5:291-300.

27. Basler G, Thompson M, Tullman-Ercek D, Keasling J. A Pseudomonas putida efflux pump acts on short-chain alcohols. Biotechnol Biofuels. 2018;11:1-10.

28. Calero P, Jensen SI, Bojanovič K, Lennen RM, Koza A, Nielsen AT. Genomewide identification of tolerance mechanisms toward $\mathrm{p}$-coumaric acid in Pseudomonas putida. Biotechnol Bioeng. 2018;115:762-74.

29. Weber FJ, Ooijkaas LP, Schemen RMW, Hartmans S, De Bont JAM. Adaptation of Pseudomonas putida S12 to high concentrations of styrene and other organic solvents. Appl Environ Microbiol. 1993;59:3502-4.

30. Li W-J, Narancic T, Kenny ST, Niehoff P-J, O'Connor K, Blank LM, et al. Unraveling 1,4-butanediol metabolism in Pseudomonas putida KT2440. Front Microbiol. 2020;11:382.

31. Nikel PI, Kim J, de Lorenzo V. Metabolic and regulatory rearrangements underlying glycerol metabolism in Pseudomonas putida KT2440. Environ Microbiol. 2014;16:239-54.

32. Hasona A, York SW, Yomano LP, Ingram LO, Shanmugam KT. Decreasing the level of ethyl acetate in ethanolic fermentation broths of Escherichia coli KO11 by expression of Pseudomonas putida estZ esterase. Appl Environ Microbiol. 2002;68:2651-9.

33. Truongvan N, Chung HS, Jang SH, Lee CW. Conserved tyrosine 182 residue in hyperthermophilic esterase EstE1 plays a critical role in stabilizing the active site. Extremophiles. 2016;20:187-93.

34. Lee C, Kim J, Hong S, Goo B, Lee S, Jang SH. Cloning, expression, and characterization of a recombinant esterase from cold-adapted Pseudomonas mandelii. Appl Biochem Biotechnol. 2013;169:29-40.

35. Tozakidis IEP, Lüken LM, Üffing A, Meyers A, Jose J. Improving the autotransporter-based surface display of enzymes in Pseudomonas putida KT2440. Microb Biotechnol. 2020;13:176-84.

36. Salvachúa D, Rydzak T, Auwae R, De Capite A, Black BA, Bouvier JT, et al. Metabolic engineering of Pseudomonas putida for increased polyhydroxyalkanoate production from lignin. Microb Biotechnol. 2020;13:290-8.

37. Chung A, Liu Q, Ouyang SP, Wu Q, Chen GQ. Microbial production of 3-hydroxydodecanoic acid by pha operon and fadBA knockout mutant of Pseudomonas putida KT2442 harboring tesB gene. Appl Microbiol Biotechnol. 2009;83:513-9.

38. Nikel PI, Chavarría M, Danchin A, de Lorenzo V. From dirt to industrial applications: Pseudomonas putida as a Synthetic Biology chassis for hosting harsh biochemical reactions. Curr Opin Chem Biol. 2016;34:20-9.

39. Nikel PI, Chavarría M, Fuhrer T, Sauer U, De Lorenzo V. Pseudomonas putida KT2440 strain metabolizes glucose through a cycle formed by enzymes of the Entner-Doudoroff, Embden-Meyerhof-Parnas, and pentose phosphate pathways. J Biol Chem. 2015;290:25920-32.

40. Bentley GJ, Narayanan N, Jha RK, Salvachúa D, Elmore JR, Peabody GL, et al. Engineering glucose metabolism for enhanced muconic acid production in Pseudomonas putida KT2440. Metab Eng. 2020;59:64-75.

41. Mezzina MP, Manoli MT, Prieto MA, Nikel PI. Engineering native and synthetic pathways in Pseudomonas putida for the production of tailored polyhydroxyalkanoates. Biotechnol J. 2021;16:2000165.

42. Weusthuis RA, Luttik MAH, Scheffers WA, Van Dijken JP, Pronk JT. Is the Kluyver effect in yeasts caused by product inhibition? Microbiology. 1994;140:1723-9.

43. Volke DC, Friis L, Wirth NT, Turlin J, Nikel PI. Synthetic control of plasmid replication enables target- and self-curing of vectors and expedites genome engineering of Pseudomonas putida. Metab Eng Commun. 2020;10:e00126.

44. Bühler B, Bollhalder I, Hauer B, Witholt B, Schmid A. Use of the two-liquid phase concept to exploit kinetically controlled multistep biocatalysis. Biotechnol Bioeng. 2003;81:683-94.

45. Verduyn C, Postma E, Scheffers WA, Van Dijken JP. Effect of benzoic acid on metabolic fluxes in yeasts: a continuous-culture study on the regulation of respiration and alcoholic fermentation. Yeast. 1992;8:501-17.

46. Batianis C, Kozaeva E, Damalas SG, Martín-Pascual M, Volke DC, Nikel PI, et al. An expanded CRISPRi toolbox for tunable control of gene expression in Pseudomonas putida. Microb Biotechnol. 2020;13:368-85. 
47. Damalas SG, Batianis C, Martin-Pascual M, de Lorenzo V, Martins dos Santos VAP. SEVA 3.1: enabling interoperability of DNA assembly among the SEVA, BioBricks and Type IIS restriction enzyme standards. Microb Biotechnol. 2020;13:1793-806.

48. National Center for Biotechnology Information. (https://www.ncbi.nlm. nih.gov/).

49. CAZy - Bacteria. (http://www.cazy.org/).

50. Van NYM, Eggink G, Weusthuis RA. Application of AlkBGT and AlkL from Pseudomonas putida GPo1 for selective Alkyl Ester $\omega$-oxyfunctionalization in Escherichia coli. Appl Environ Microbiol. 2016:82:3801-7.

51. Worsey MJ, Williams AP. Metablism of toluene and xylenes by Pseudomonas putida (arvilla) mt-2: evidence for a new function of the TOL plasmid. J Bacteriol. 1975;124:7-13.
52. Bagdasarian MM, Lurz R, Riickert B, Frey J, Timmis KN. Specific-purpose plasmid cloning vectors II. Broad host range, high copy number, RSF1010-derived vectors, and a host-vector system for gene cloning in Pseudomonas. Gene. 1981;16:237-47.

\section{Publisher's Note}

Springer Nature remains neutral with regard to jurisdictional claims in published maps and institutional affiliations.
Ready to submit your research? Choose BMC and benefit from:

- fast, convenient online submission

- thorough peer review by experienced researchers in your field

- rapid publication on acceptance

- support for research data, including large and complex data types

- gold Open Access which fosters wider collaboration and increased citations

- maximum visibility for your research: over $100 \mathrm{M}$ website views per year

At BMC, research is always in progress.

Learn more biomedcentral.com/submissions 